\title{
Study on the Application of Mobile Learning in Traditional Teaching---Elements of Information Theory Course as a Study Case
}

\author{
Rong $\operatorname{Tan}^{1, a}$, Xiaolei $\operatorname{Han}^{1, b}$ and Wen $\mathrm{Si}^{1, \mathrm{c}}$ \\ ${ }^{1}$ Department of Information and Computer Science, Shaghai Business School, Shanghai, China; \\ atanrong529@gmail.com, b hxl_regina@163.com, 'siw@sbs.edu.cn
}

Keywords: M-Learning, Fragmented Learning, Microlecture, Gamification.

\begin{abstract}
The M-learning has brought significant opportunities and challenges for higher education. By analyzing on the relationship between M-learning and traditional teaching as well as adopting the Elements of Information Theory course as a study case, this paper investigated the methods to retrieve the fragmented knowledge units from the fundamental theoretical knowledge architecture which can be displayed by the microlectures. Furthermore, a classroom-game is designed to explore the influence of gamificaiton on traditional teaching. The results show that the M-learning and gamification greatly improve the education effects.
\end{abstract}

\section{Introduction}

With the popularity of smart mobile devices and the rapid development of mobile Internet, the traditional classroom teaching modes are facing new opportunities and challenges. Among them, M-Learning has exerted the widest influence [1-3]. M-Learning, as a new learning mode in recent years, is considered to be the extensions of E-Learning [4]. Being quite different from E-Learning, M-Learning puts emphasis on mobility. To be specific, in the process of M-Learning, mobile devices, such as smart phone and tablet, become the main learning interaction tools by replacing desktop computers, and learners can study anytime and anywhere rather than under the fixed environment. These changes have greatly promoted the reform of traditional teaching modes. At present, more and more education institutions and researchers across the world begin to research and adopt E-Learning method to enhance the teaching effect [5-7].

Although M-Learning has become a research hotspot in the related fields, there has been no unified definition of it. It can be roughly divided into the following categories: 1) M-Learning refers to all teaching modes that use a variety of mobile devices as the main teaching tools in general; 2) M-Learning is regarded as the extension of E-Learning and a kind of mobile E-Learning; 3) all kinds of learners-oriented learning which the learning environment is not fixed, or which the study places are not planned ahead can be thought as M-Learning [8]. The above three views define M-Learning respectively from the perspectives of learning tools, learning form and learning environment. They are different but include the same connotation. The properties of learning tools, learning form, and learning environment are necessary for M-Learning.

M-Learning, of course, changes the traditional teaching modes not only in terms of learners, but also puts forward higher requirements for teachers. From the perspective of teaching contents, the traditional teaching modes have fixed and comparably longer time, so contents are generally based on chapters, and cover complete knowledge points. By contrast, under the situation of vast majority of M-Learning, teaching contents must be brief, and usually include one knowledge point. It is a kind of "fragmented" learning due to the limit of environment and time. Thus, teachers need to hackle, subdivide and reorganize the curriculum knowledge modules. However, even if they can scientifically fragmentize the contents, how to enable the learners to grasp the relationship between fragmentation and entirety and finally master the knowledge from the comprehensive aspect, and how to evaluate the effect of fragmented learning, and whether it can achieve the expected teaching goals are important challenges. 
From the perspective of the relations between learners and teachers, M-Learning significantly enhances the interaction between them leading to a closer relationship. In the traditional teaching, there is a kind of a face-to-face studying and teaching process, and teachers deliver the contents to learners within limited time. In fact, learners and teachers have less communication in class. It tends to cause unsatisfactory teaching effect once the learners face difficulties. By contrast, in M-Learning, learners and teachers can communicate regardless of the limited time and place, and learners can feed back to teachers in time according to their own learning situation. However, because of the lack of attendance constraints, teachers often fail to grasp students' learning progress, and also face big challenges in motivating the studying enthusiasm and interest.

In fact, M-Learning and traditional classroom teaching modes are not mutually exclusive. According to the recent research of the US. Department of Education, "mixed teaching"--the combination of M-Learning and classroom teaching has improved students' achievements by $14 \%$. Thus, the combination of M-Learning and classroom teaching not only reduces the limits of time and place for learners in the process of learning, but also enhances the freedom for teachers, and achieves the better teaching effect.

In this paper, with the Elements of Information Theory which is a fundamental course for the students majored in Electronic Information Engineering as the study case, the in-depth research is conducted on the application of M-Learning in the traditional teaching. The course Elements of Information Theory applies the modern probability statistical method to study the information transmission, transformation, storage and processing, and it focuses on the relevant concepts and properties of entropy as well as the coding theory and methods which contains a large number of theorems and mathematical formulas. In the process of traditional classroom teaching, students often feel bewildered in the face of the complicated and boring theorems and formulas, which causing the poor learning effect. Therefore, in order to improve the teaching effects, how to combine M-Learning with traditional classroom teaching in the field of science and engineering teaching has been generally studied and explored.

\section{From Comprehensive Knowledge to Fragmented Knowledge}

The knowledge in M-Learning is featured by "fragmentation". On the one hand, it refers to the fragmentation of knowledge information, because M-Learning turns the complete and systematical knowledge into scattered knowledge units, which can be a knowledge point of a curriculum, a small video of popular science, and even just one English word. On the other hand, "fragmentation" also means the fragmentation of learning time, because M-Learning turns the fixed learning period to trivial time in daily life, such as commuting time. Through the gradual accumulation of information and knowledge, learners will increase knowledge and acquire skills. Especially in the current era of information explosion, the new knowledge and ideas emerge in endlessly. In addition, as the fast rhythm of life and work, people's leisure time has been significantly shortened. All of the factors above make the fragmented M-Learning grow and develop rapidly.

In order to ensure learners have the fragmented learning anytime and anywhere, teachers need to divide the teaching contents into several small knowledge pints, and organize them into the corresponding teaching units. Besides, to make the learning simpler in the process, teachers may tend to isolate knowledge points, and only provide the superficial knowledge to learners, without involving the specific principle behind it, and the connection between it and other knowledge. As a result, learners will only see the part but neglect the whole. Lack of systematic study, they will finally fail to master the complete knowledge structure.

Therefore, in order to better achieve teaching goals and enable learners to grasp complete and comprehensive teaching contents, it is obviously unwise to adopt simple knowledge classification method. Teachers must first summarize the whole knowledge hierarchy from the global perspective, reasonably and scientifically divide the contents into knowledge modules, and then refine important and independent knowledge points, and finally form the fragmented teaching contents so as to avoid learners' one-sided understanding. At the same time, in the process of specific refinement of 
knowledge, it is advisable for teachers to use the modern knowledge management technologies, such as "knowledge map" [9] or "knowledge graph" [10] to establish more detailed knowledge structure relationship diagram, and realize the navigation and localization of knowledge, as well as knowledge sharing and communication more easily.

To sum up, for a particular course, the fragmentation process of its knowledge mainly consists of the following steps:

1. Identifying the core research objects and problems.

2. Recognizing the important concepts, concept attributes, and the relationship between concepts included in the core objects and problems.

3. Extracting the identified objects of knowledge, establishing the connections, and considering it as the top level of knowledge.

4. Based on the extracted objects of knowledge, continue to identify the important concepts, concept attributes and the relationships between concepts and establish connections with each other.

5. Executing Step 4 repeatedly until no more concept objects can be identified.

Moreover, in order to make the constructed knowledge diagram be better understood, and be expanded and updated more easily, it should reduce the control of the sub-layer structure and not be confined to the relationship between superordination and subordination and the same level. On the one hand, there are usually complicated relationships between concepts, so the fixed hierarchical approach is not conducive to understand and build the relationship diagram; on the other hand, knowledge itself keeps emerging and updating all the time, which is a dynamic process, so the flexible levels and structures also helps for subsequent extension in the future.

The paper takes the course Elements of Information Theory as an example, of which core issue is to study how to efficiently and reliably transmit the information. Therefore, its study object is the general communication system, and it abstracts all of information circulation system to a unified model (see Fig. 1). In addition, the key points of knowledge are the concepts of entropy and coding. According to the communication system model, the specific knowledge points are distributed in five parts, namely, information source, encoder, information channel, decoder and information sink.

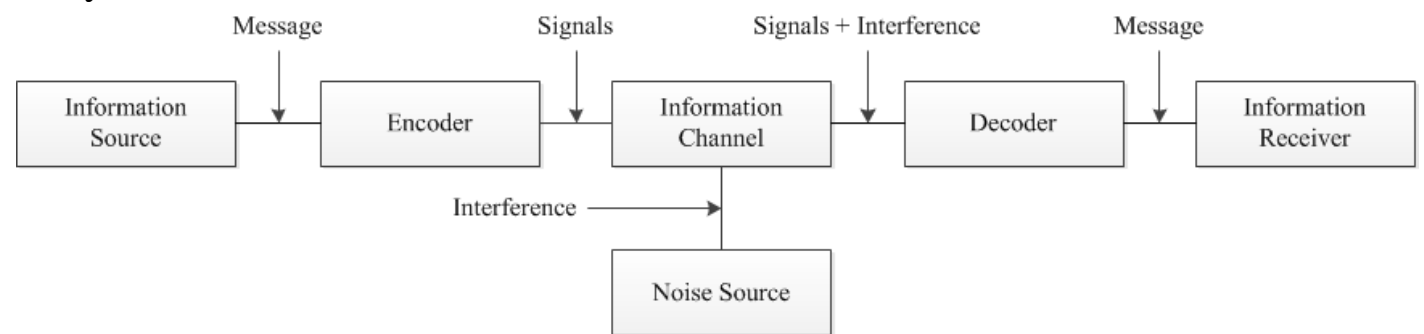

Fig. 1 Communication System Model

Therefore, for the course Elements of Information Theory, its research object is the communication system model, which can be considered as its top knowledge hierarchy; its key knowledge points are entropy and the relevant concepts, which can be regarded as the basis of knowledge structure; the five important components in the model (information source, encoder, information channel, decoder and information sink) can be thought as the main knowledge modules; the communication between modules is the transitive relation of information in the different links of communication system. Then, more detailed division of knowledge in the different knowledge modules from parts to the whole is able to be conducted. Because the top knowledge layer and the relationships between modules have already been identified, fragmented knowledge does not exist in the isolated form, and can be mutually related through the relationship between modules.

Fig. 2 shows the part of knowledge structure diagram of Elements of Information Theory based on the subdivision principle of mentioned above (to ensure readability, only the related part of "information source" is included). In the diagram, orthogonal rectangle represents the top knowledge point; rounded rectangle represents the knowledge point after carding and subdivision; oval represents the important concepts and concept attributes included in the related knowledge points; the different shapes are connected by arrows indicating the specific relationships which are annotated in 
the lines. The diagram clearly shows the explicit relationships between superordination and subordination derived according to the different relationships of the knowledge points. To be specific, the knowledge points at lower level which including more specific knowledge points are more suitably considered as fragmented knowledge.

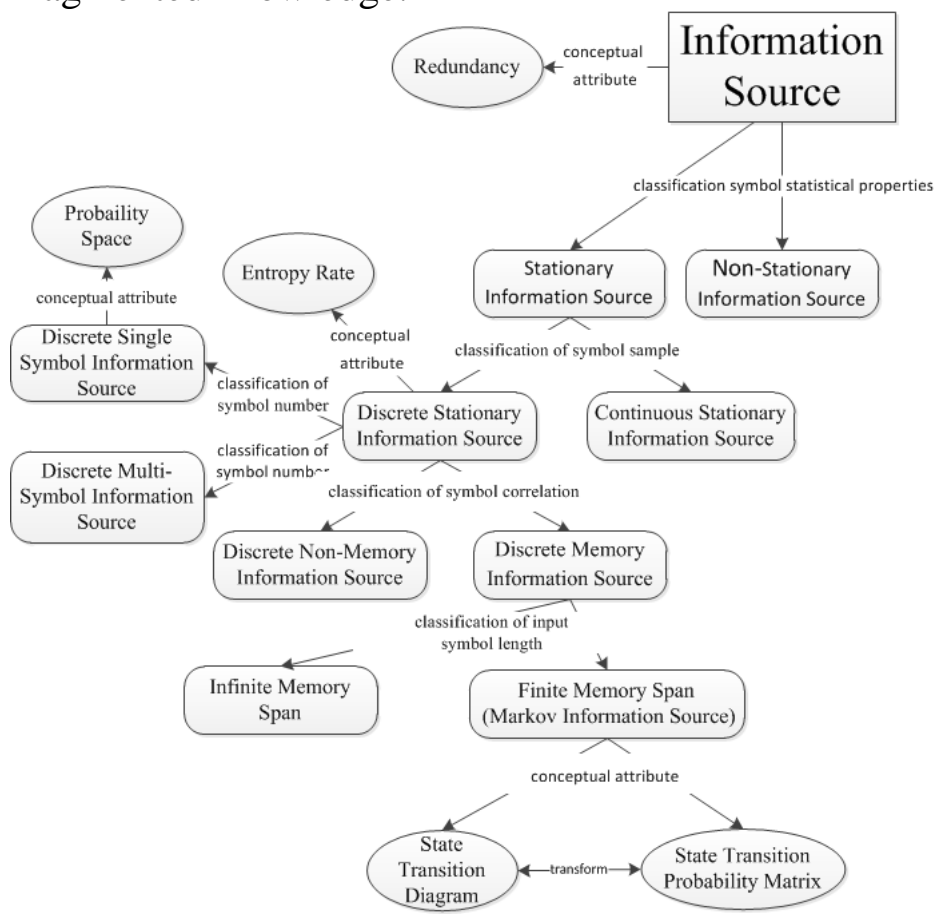

Fig. 2 Part of the Knowledge Diagram of Elements of Information Theory

\section{Presentation of Fragmented Knowledge with Microlecture}

With the development of mobile Internet, as well as the advance in communication and multimedia technologies in recent years, great changes have taken place in the presentation forms of learning content in M-Learning. In the past, the learning contents were often shown to learners in the form of the text along with pictures. Although this way is simple and intuitive, and takes less cost of communication, it has many obvious shortcomings.

On the one hand, the static text and pictures are lack of change, which tends to make learners feel dull and tired. Even the dynamic image technology, such as GIF is adopted, it may be still not quite vivid due to the lack of corresponding voice narrator. On the other hand, most of mobile terminal devices have smaller screen size (for example, smart phone screen is only about 5 inches), so it is very difficult and obviously unacceptable to explain a knowledge point clearly through a large number of words and pictures. Thereby, more and more teachers begin to adopt the form of "microlecture" to show teaching contents.

Microlecture[11], a kind of teaching form rising in recent years, often concentrates on one certain knowledge point or skill, and shows it to learners through a short time of multimedia video. It is featured by a clear goal within a short time period which makes it accord with the requirements of M-Learning. Moreover, the kind of vivid display is particularly significant for M-Learning of science and engineering courses.

"Coding", for example, an important concept in the course Elements of Information Theory, involves each module of whole communication system model. Each kind of coding has its specific algorithm steps, so it is difficult to clearly explain them only with static texts. In the traditional classroom teaching, teachers usually explain the algorithm via text in general, and then have detailed explanation gradually through certain example, so it can be regarded as a dynamic teaching process. Additionally, when making microlecture video, teachers can also adopt multimedia technology to make a more attractive demonstration effect which differs from the traditional blackboard writing method, and then emphasize the focal point more clearly. 
Teachers need to make detailed plans in advance when they want to produce the fragmented knowledge into microlecture video. With "Shannon Coding" in the course Elements of Information Theory as an example, the schedule of the microlecure video is made as shown in Table 1 below:

Table 1 Microlecture Video Design of Shannon Coding

\begin{tabular}{|c|c|c|c|}
\hline Numble & Description & Narration & Duration \\
\hline 1 & $\begin{array}{l}\text { Introduction: Shannon } \\
\text { Coding with Fisrt } \\
\text { Shannon Coding }\end{array}$ & $\begin{array}{l}\text { The Shannon Theorem points out that the relationship } \\
\text { between average code length and source information } \\
\text { entropy. However, it does not provide a method to } \\
\text { build the optimum code. Therefore, in this lecture, the } \\
\text { Shannon Coding which can be used to retrieve the } \\
\text { optimum code is introduced. }\end{array}$ & $30 s$ \\
\hline \multirow[t]{6}{*}{2} & $\begin{array}{l}\text { Theme: steps of Shannon } \\
\text { Coding }\end{array}$ & $\begin{array}{l}\text { Narrate the four steps of Shannon Coding: } \\
\text { (1) Arrange informations source symbols in the form } \\
\text { of decreasing probability: }\end{array}$ & $1 \mathrm{~m} 30 \mathrm{~s}$ \\
\hline & & $P\left(a_{1}\right) \geq P\left(a_{2}\right) \geq \mathrm{L} \geq P\left(a_{r}\right)$ & \\
\hline & & $\begin{array}{l}\text { (2) calculate the code length of each symbols by: } \\
\qquad l_{i}=\left\lceil-\log P\left(a_{i}\right)\right\rceil, \quad(i=1,2, \ldots, r)\end{array}$ & \\
\hline & & $\begin{array}{l}\text { (3) calculate the cumulative probability of the i-th } \\
\text { symbol by: }\end{array}$ & \\
\hline & & $Q_{i}=\sum_{k=1}^{i-1} P\left(a_{k}\right), \quad(i=1,2, \ldots, r)$ & \\
\hline & & $\begin{array}{l}\text { (4) tranform the cumulative probability Qi in binary. } \\
\text { (5) let the last li length of the number after the decimal } \\
\text { point be the corresponding code }\end{array}$ & \\
\hline 3 & $\begin{array}{l}\text { Example: examples of } \\
\text { Shannon Coding }\end{array}$ & $\begin{array}{l}\text { Explain the details of an example of Shannon Coding } \\
\text { with four steps mentioned above. }\end{array}$ & $4 \mathrm{~m}$ \\
\hline 4 & $\begin{array}{l}\text { Summary: Summzrize } \\
\text { and give the assignment }\end{array}$ & $\begin{array}{l}\text { Shannon Coding is a classic coding method. It uses } \\
\text { the shorter code word for the source symbol with } \\
\text { higher probability, and the longer code for the symbol } \\
\text { with less probability, so that the average code length } \\
\text { tends to be the shortest, and the best encoding is } \\
\text { achieved. }\end{array}$ & $1 \mathrm{~m}$ \\
\hline
\end{tabular}

In addition, to achieve better learning effect and evaluate learning effect timely, teachers also need to design corresponding after-class activity lists (such as the arrangement of thinking and discussion after class) when making the microlecture courseware, as shown in the Table 2.

Table 2 Microlecutre Learning Activity Design of Shannon Coding

\begin{tabular}{|c|c|c|c|}
\hline Numble & Purpose & Content & Specification \\
\hline 1 & $\begin{array}{l}\text { Review the learning } \\
\text { contents of last course, and } \\
\text { import the knowledge of the } \\
\text { course }\end{array}$ & $\begin{array}{l}\text { Ask students to discuss how to } \\
\text { encode information source } \\
\text { symbols and what they will do }\end{array}$ & $\begin{array}{l}\text { Students have discussion after } \\
\text { class in group of } 5 \text { ones, and } \\
\text { express their group ideas on } \\
\text { the next lecture. }\end{array}$ \\
\hline 2 & $\begin{array}{l}\text { Dicussion about the ideas of } \\
\text { Shannon Coding }\end{array}$ & $\begin{array}{l}\text { Ask students to discuss ideas } \\
\text { about Shannon Coding, and } \\
\text { whether they think it is a good } \\
\text { coding way in combination } \\
\text { with Shannon theorem }\end{array}$ & $\begin{array}{l}\text { Students have discussion after } \\
\text { class in group of } 5 \text { ones, and } \\
\text { express their group ideas on } \\
\text { the next lecture. }\end{array}$ \\
\hline
\end{tabular}

Besides, teachers need to design the related learning evaluation table (see Table 3), so as to effectively evaluate learners' mastery degree of the knowledge and better grasp the learning situation.

Table 3 Microlecture Learning Evaluation Design of Shannon Coding

\begin{tabular}{clll}
\hline Numble & \multicolumn{1}{c}{ Purpose } & \multicolumn{1}{c}{ Content } & \multicolumn{1}{c}{ Standard and Specification } \\
\hline 1 & $\begin{array}{l}\text { To evaluate learners' mastery } \\
\text { degree of the teaching } \\
\text { knowledge ---Shannon Coding }\end{array}$ & & $\begin{array}{l}\text { Judge by the correctness of the } \\
\text { after-class homework; students } \\
\text { should think independently and } \\
\text { complete them by themseleves. }\end{array}$ \\
\hline
\end{tabular}

By carding course knowledge hierarchy, teachers can make the refined teaching emphasis and difficulties into microlecture form. Even if students fail to master the knowledge in the classroom 
learning, they also can consolidate the knowledge by watching related microlectures and completing the after-class activities and homework in M-Learning.

\section{Motivating the Learning Enthusiasm by Gamification}

How to arouse learners' learning enthusiasm and create good learning atmosphere has been one of the hot issues in the researches of pedagogy. Science and engineering specialties, in particular, put much emphasis on solid theoretical foundation, and many courses contain a large number of complicated theorems and formulas which seems relatively boring which results in depressing atmosphere and low learning enthusiasm. On the other hand, with the popularity of smart devices and the development of mobile Internet, mobile phones and other mobile devices have become important interference factors of classroom teaching. In order to solve these problems, domestic and foreign relevant experts have made many explorations and attempts among which the "Gamification" is one of the most popular research directions. Khan Academy in the United States designs the boring mathematics, physics, and chemistry classroom like playing games, promotes the individualized teaching and creates "Flipped Classroom" which increase the initiative of learners.

In fact, education and game have never been incompatible as education in amusement is always encouraged. At present, the gamification in the classroom teaching mainly refer to the employment of PBL(Point, Badge and Leader-board) of game: 1) point can be accumulated or used to determine the status of winning. And at the same time, point is linked to rewards, and also can be used as a kind of reference and feedback; 2) badge represents a kind of achievement, or a kind of learning style, and plays an important role in identification just like a milestone; 3) Leader-board reflects the ultimate learning status and achievement.

In order to explore the application effect of gamification in science and engineering specialties, a "challenge game" based on mobile network platform for the course Elements of Information Theory is designed, with the specific rules as follows:

1. The whole class is divided into several groups with about five students in each group (group number must be even).

2. According to the round-robin tournament, the groups will be divided into challenge groups and against groups, and compete with each other every week.

3. The challenge group raises any number of questions (generally no more than five ones) within the scope of learning contents.

4. The total scores are 10 points, and the specific score of each question is determined by the challenge group.

5. The challenge group needs to release the questions to the entire class on the mobile social networking platform a week ahead, and the other groups has a week of time to think about how to answer these questions.

6. If the against group fails to answer the questions in the class, then other groups also have the opportunities to answer and score as long as they answer correctly.

7. At the end of the round-robin tournament, each group will be ranked according to scores, which will be reflected in the final course grade. For example, assuming there are six groups in all, groups ranking by 1-2-3-4-5-6 will earn the additional 6-5-4-3-2-1 scores in their final grades. The champion group, of course, will gain additional prize from the teacher.

The introduction of gamification makes the classroom atmosphere become more active obviously that the students have higher participating enthusiasm. It helps to improve the teaching effect and achieve the expected goals as well. The comparisons before and after the "challenge game" is adopted in the course Elements of Information Theory with two different grades are proposed in Fig.3. Fig. 3(a) shows the comparison results of class attendance rate. The overall attendance rate of the class (shown with the dot pattern on the left side) which doesn't adopt the "challenge game" is $85.3 \%$, while that of the class (shown with the diamond pattern on the right side) which adopts the "challenge game” increases to $96.67 \%$. At the same time, Fig. 3(b) shows the comparison of average final score. The score of the former class is 74.37 , while that of the later class is 81.5 . It is obvious that the 
“Gamification”, to a certain extent, improves students’ learning enthusiasm and has positive effect in creating active classroom atmosphere.

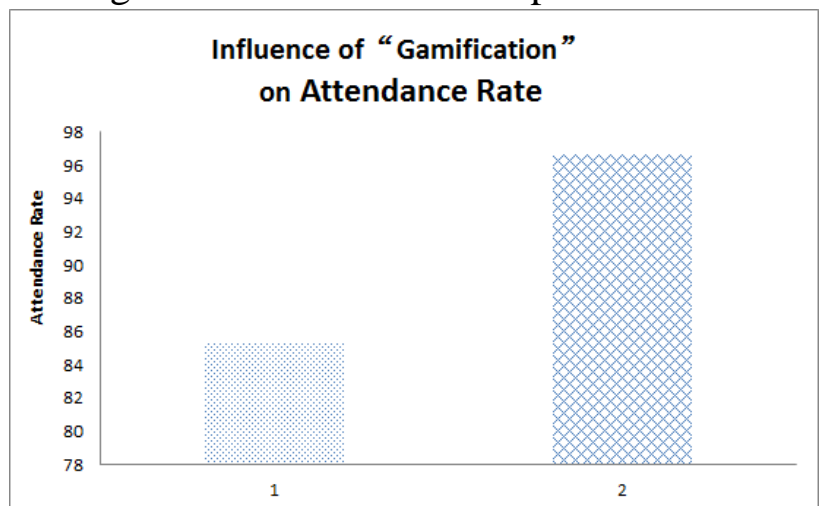

(a)

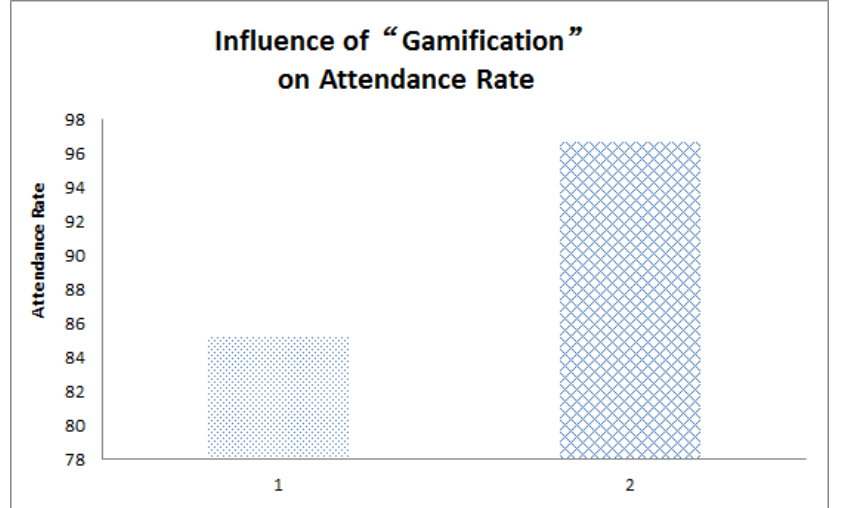

(b)

Fig. 3 (a) Influence of Gamification on Attendance Rate; (b) Influence of Gamification on Average Final Score

In addition to "Gamification", some mobile social software, such as QQ and WeChat can also increase the interactions between teachers and students. After joining in the discussion groups organized by students, teachers can communicate with them anytime and anywhere, answer the questions, get teaching feedbacks and timely adjust the teaching schedules.

\section{Summary}

The development of modern communication technology, as well as the popularization of mobile intelligent devices has brought unprecedented opportunities for higher education. Utilizing the M-Learning to meet the increasingly diverse needs of learners has gradually become one of the best choices to improve the teaching effects for colleges and universities. However, M-Learning and traditional classroom teaching also face numerous challenges. For example, how to effectively hackle the knowledge hierarchy, refine the knowledge modules, make knowledge accord with the requirement of fragmented learning, create good learning atmosphere, establish good interactions, make learners study spontaneously and consciously are still needed to be further studied.

Based on the in-depth analysis of the relationship between M-Learning and traditional classroom teaching, the "fragmented" approach of the course knowledge hierarchy is studied, and how to render the refined "fragmented" knowledge through microlecture technology is discussed as well with the course Elements of Information Theory as a study case. At the same time, the "challenge game" is introduced. Students' learning enthusiasm is improved and the classroom teaching effect has been greatly increased after adopting the "Gamification". It is hoped that the research has some reference value for subsequent reteaches in colleges and universities.

\section{References}

[1] Sharples, M. Learning as conversation: Transforming education in the mobile age, Proceedings of Seeing, Understanding, Learning in the Mobile Age, 2005, pp. 147-152.

[2] Kim, Paul, et al. "Socioeconomic Strata, Mobile Technology, and Education: A Comparative Analysis.” Educational Technology Research and Development, Volume 59, 2011, pp. 465-486.

[3] Fátima David, Rute Abreu, Information Technology in Education: Recent Developments in Higher Education, 9th Iberian Conference on Information Systems and Technologies (CISTI), 2014, pp 1-6

[4] Traxler, J. Mobile learning its here but what is it? Interactions, 9,1. University of Warwick, 2005. 
[5] Boyinbode, O., Bagula, A., \& Ngambi, D. An Opencast Mobile learning Framework for Enhancing Learning in Higher Education. International Journal Of U- \& E-Service, Science \& Technology, 4(3), 2011, pp.11-18.

[6] Charalampos Giousmpasoglou, Evangelia Marinakou, The future is here: m-learning in higher education, 2013 Fourth International Conference on e-Learning "Best Practices in Management, Design and Development of e-Courses: Standards of Excellence and Creativity, 2013, pp. 417-420.

[7] Al-Fahad, F.N. Students’ Attitudes and Perceptions towards the Effectiveness of Mobile Learning in King Saud University, Saudi Arabia. TOJET: The Turkish Online Journal of Educational Technology, 8(2), 2009, Article 10.

[8] O’Malley, C., Vavoula, G., Glew, J., Taylor, J., Sharples, M. \& Lefrere, P. (2003) Guidelines for learning/teaching/tutoring in a mobile environment. Mobilearn project deliverable. Available from http://www.mobilearn.org/download/results/guidelines.pdf, last accessed 27th March 2006.

[9] Shaw.r.s. a study of learning performance of e-learning materials design with knowledge map[j].computers\&education, 2010, 54(1):253-264

[10] Singhal, A.: Introducing the Knowledge Graph: Things, Not Strings (2012) Official Blog (of Google), see: http://goo.gl/zivFV

[11] Li, J. H. The Significance and Development of Microlecture. Journal of Information Technology in Middle School and Elementary School, 4, 2014, pp.10-12.

[12] Deterding, S., Khaled, R., Nacke, L.E., Dixon, D., 2011b. Gamification: toward a definition. In: Proceedings of the CHI 2011 Gamification Workshop Proceedings. Presented at CHI 2011. ACM, Vancouver, BC.

[13] Khan Academy, https://cmn.khanacademy.org/ 